\title{
Retraction Note: Wireless sensor-based prediction of debris flow in mountainous areas and improvement of power business environment
}

\author{
Xinnan Zhou ${ }^{1}$ Shuochen $\mathrm{Han}^{2} \cdot$ Zuofang Liang $^{3} \cdot$ Xiaobo Yang $^{1}$
}

Published online: 17 November 2021

(c) Saudi Society for Geosciences 2021

Retraction Note: Arabian Journal of Geosciences (2021) 14: 1493 https://doi.org/10.1007/s12517-021-07754-4

The Editor-in-Chief and the Publisher have retracted this article because the content of this article is nonsensical. The peer review process was not carried out in accordance with the Publisher's peer review policy. Authors Xinnan Zhou, Zoufang Liang and Xiaobo Yang have not responded to correspondence regarding this retraction. The Publisher has not been able to obtain a current email address for author Shouchen Han.

The original article can be found online at https://doi.org/10.1007/ s12517-021-07754-4.

Zuofang Liang fblw8926@163.com

1 Marketing Service Center (Metering Center) of State Grid, Jibei Electric Power Co., Ltd, Beijing 100045, China

2 State Grid Jibei Electric Power Co., Ltd, Beijing 100045, China

3 Heze Power Supply Company of State Grid Shandong Electric Power Company, Heze 27400, Shandong, China 